\title{
Meter-testing methods matter
}

\author{
DEVAN J. SHIELDS, ${ }^{1}$ STEVEN L. BARFUSS, ${ }^{2}$ MICHAEL C. JOHNSON, ${ }^{2}$ \\ AND CRAIG C. HANNAH ${ }^{3}$
}

\author{
${ }^{1}$ Kimley-Horn and Associates, Ft. Worth, Texas \\ ${ }^{2}$ Utah Water Research Laboratory, Logan, Utah \\ ${ }^{3}$ Johnson Controls Inc., Lubbock, Texas
}

Even though many water utilities in the United States perform some form of water meter testing, little has been published concerning utility meter accuracy-testing procedures. Although AWWA's Manual M6, Water Meters-Selection, Installation, Testing, and Maintenance (2012), provides much useful information concerning accuracy-testing principles, the recent development of static residential water meters has introduced new questions about accuracy-testing procedures that are not addressed in the current edition of M6. This article discusses the results of a study performed at the Utah Water Research Laboratory (UWRL) that involved sending a set of meters to various utility meter shops around the country to be tested. The UWRL tested the meters both before and after the tests were performed at each utility. Each utility forwarded a copy of its accuracy test results to the UWRL, and the results from each utility were then compared with the UWRL test results.

Keywords: water meter testing, meter test bench accuracy

Even though many water utilities in the United States perform some form of meter testing, little has been published concerning utility meter accuracy-testing procedures. AWWA's Manual M6, Water Meters-Selection, Installation, Testing, and Maintenance (2012) is arguably the most common reference. Although M6 provides much useful information about accuracy-testing principles, the recent development of static residential water meters has raised new questions that are not addressed in the current edition. The 1991 report, Evaluating Residential Water Meter Performance (Bowen), discusses water meter testing procedures and is useful with regard to meter-endurance testing.

This article discusses the results of a study performed at the Utah Water Research Laboratory (UWRL) that involved sending a set of meters to various utility meter shops around the country to be tested. The UWRL shipped sets of 10 new 5/8 $\times 3 / 4$-in. meters to 12 utilities in the United States. Each utility tested the meters at the M6 recommended minimum test flow rate, intermediate test flow rate, and maximum test flow rate of $0.25,2$, and 15 gpm, respectively. URWL tested the meters both before and after the utility tests. Each utility forwarded a copy of its accuracy test results to the UWRL, and the results from each utility were then compared with the UWRL test results.

The primary objectives for this research project were to illustrate to utilities that have active meter-testing programs that meter testing methods matter, and to develop suggestions about how utilities can improve their meter-testing methods. The authors suggest that the lessons learned from this effort, in addition to the topic of testing residential static meters, be addressed in future editions of M6.

\section{RESEARCH APPROACH}

The authors compared the meter-accuracy test results performed at 12 utilities in the United States on sets of 10 residential meters to the results from accuracy tests performed on the same meters at the UWRL. To reduce the time required for the study, the UWRL used two sets of 10 meters, each consisting of two displacement piston (DP), two multijet (MJ), two single-jet (SJ), two fluidicoscillator (FO), and two nutating-disc (ND) meters. Each participating utility tested one of the sets of 10 meters at the minimum, intermediate, and maximum test flow rates relevant to the meter size. In return, the UWRL provided each utility with a copy of the UWRL test data for that meter set to which their own data could be compared.

UWRL accuracy tests. The UWRL performed accuracy tests on its gravimetric bench both before and after each utility performed its accuracy tests on the 10 meters. This procedure ensured that the meter accuracies did not change during shipping or as a result of misuse or damage. The UWRL used calibrated electromagnetic meters to set target flow rates, and the flow rates were doublechecked during the run by recording the time elapsed during each test and net weight of water collected. The UWRL used a constant-head reservoir to provide an absolute steady-flow rate for the minimum flow rate tests. Higher flow rate tests used pressurized city water.

During the UWRL tests, water flowed through the meters and into one of two weigh tanks-a smaller tank with a higher-resolution scale for the minimum flow rates and a larger tank for the higher flow rates. Technicians recorded the water temperature during each test to obtain the precise unit weight of water that could be used in 
conjunction with the measured weight to accurately calculate the measured water volume. The laboratory regularly calibrates the weight tank scales, and the laboratory is certified by the National Institute of Standards and Technology. For each flow rate tested, technicians manually read the meter registers and recorded the data before and after each test. This information was then compared with the collected volume in the weigh tank.

Utility accuracy tests. Most of the utilities performed the tests using volumetric test benches like those shown in the photograph to the right. Each participating utility submitted photographs of their respective test setup and a basic procedural outline that was followed during meter testing. Test setup and reporting precision varied among different utilities, with some utilities testing all 10 meters at once and others testing smaller groups. Some utilities reported meter accuracy only to the nearest $1 \%$. One utility used only a portable test meter and another used a gravimetric test bench. All of the participating utilities were asked to test the meters in the manner that is normally used to test their own meters. All parties agreed that the results from each participating utility would remain anonymous.

\section{TEST RESULTS}

The before-and-after tests performed at the UWRL yielded consistent results throughout the study. The UWRL test results, as well as the utility test results, are shown in Figures 1-3. The results shown in those figures are averages of the test results for all 10 meters tested. UWRL results in these figures are averages of tests from before and after each utility test.

It is not surprising that the most significant differences in average test results between the UWRL standard and a given utility occurred at the minimum test-flow rate $(0.25 \mathrm{gpm})$. Errors typically occur at minimum flow rates when the available instrumentation does not have a small enough gradation on the scale or when sufficient volumes are not collected in order to minimize the uncertainty of the measurement. The largest difference between the UWRL results and those from a utility occurred with utility 12 . This was the only participating utility that used a portable master test meter and tested the meters

FIGURE 1 AWWA minimum flow rate $(0.25 \mathrm{gpm})$ test results showing the average accurWy for all 10 meters in the set

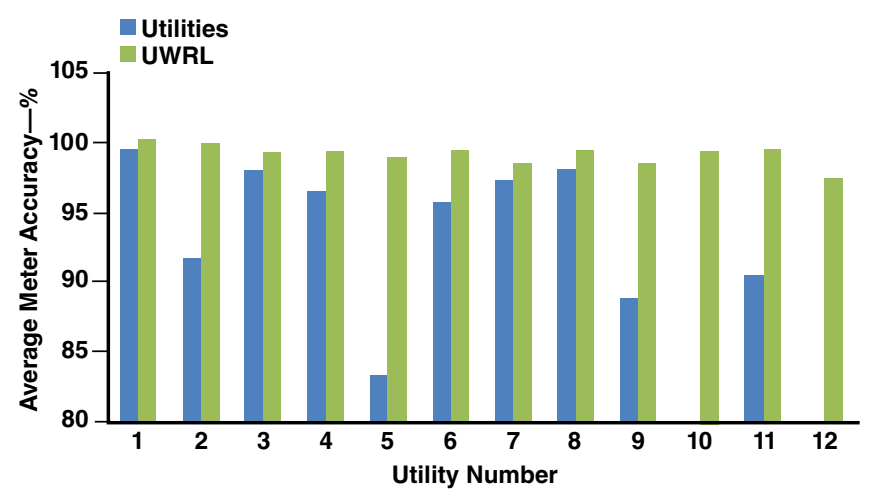

UWRL—Utah Water Research Laboratory

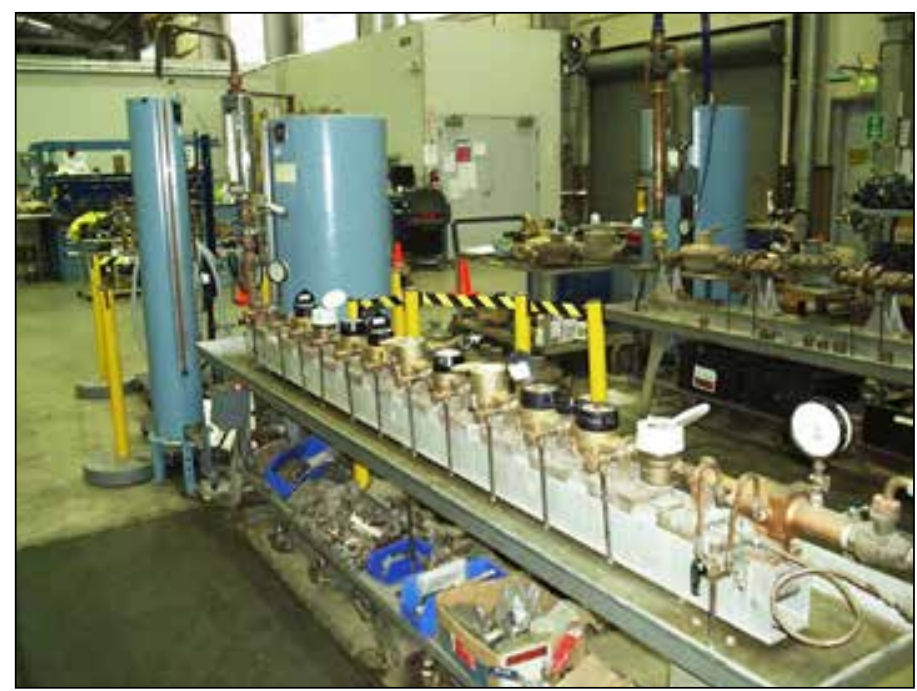

Typical utility test bench setup, showing test meters in series and collection tanks. (Photograph used with permission)

individually. For the most part, utility measurements were reasonably close to the UWRL results at both the intermediate and maximum flow-rate tests.

Meter type sensitivity to testing setup. One finding not anticipated by the authors was the difference in test results among different meter types. Figure 4, which shows the average difference between utility test bench results and UWRL tests on each meter type at minimum, intermediate, and maximum flow rates, illustrates this observation. The figure was generated by averaging the difference between the UWRL tests and utility tests for each meter type. Data from utility 12 were excluded from the analysis shown in Figure 4 because those test results were considered unreliable.

Although all of the meters represented in the figure were tested on test benches, the test setups varied between different utilities and the UWRL test bench. Several variations in meter

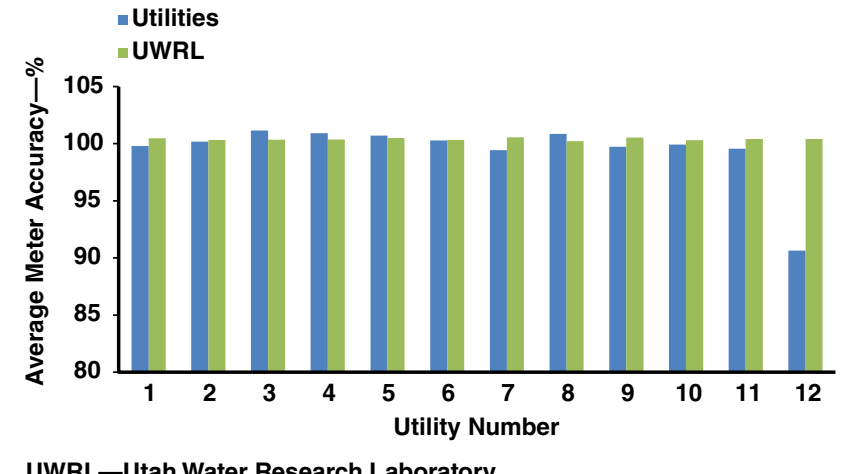

UWRL-Utah Water Research Laboratory 


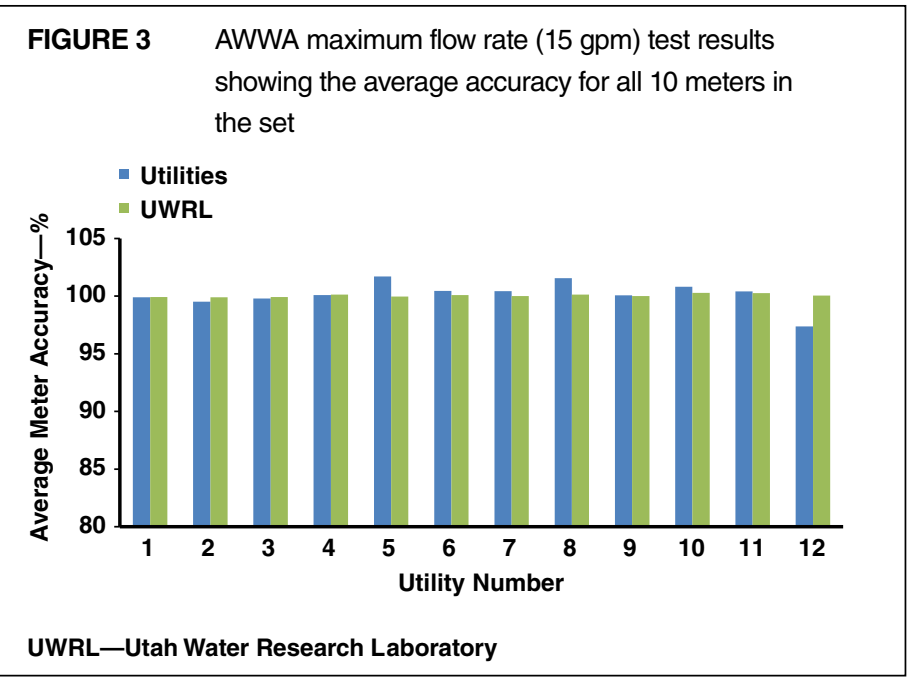

sequence, the number of meters tested in each run, system pressure, and the spacing between meters in series were shown in the photos and descriptions submitted by the participating utilities. Instructions in M6 do not address those aspects of meter testing, except for suggesting the use of intermediate couplers and providing nonpulsating flows when testing several MJ meters at once (AWWA, 2012). Given this background, these variations are to be expected and provide some insight into possible sources of error in meter testing. The differences shown in Figure 4 basically compare the sensitivity of the different meter types to the test setup.

The FO meters showed the greatest sensitivity to flow disturbances at the minimum test flow rate, averaging a $32 \%$ difference between the UWRL and utility test results. DP meters showed the least variation between the two groups of results at the minimum test flow rate, averaging a difference of only $1.6 \%$.

\section{FIGURE 4 Average difference between utility test bench results and UWRL results by meter type}

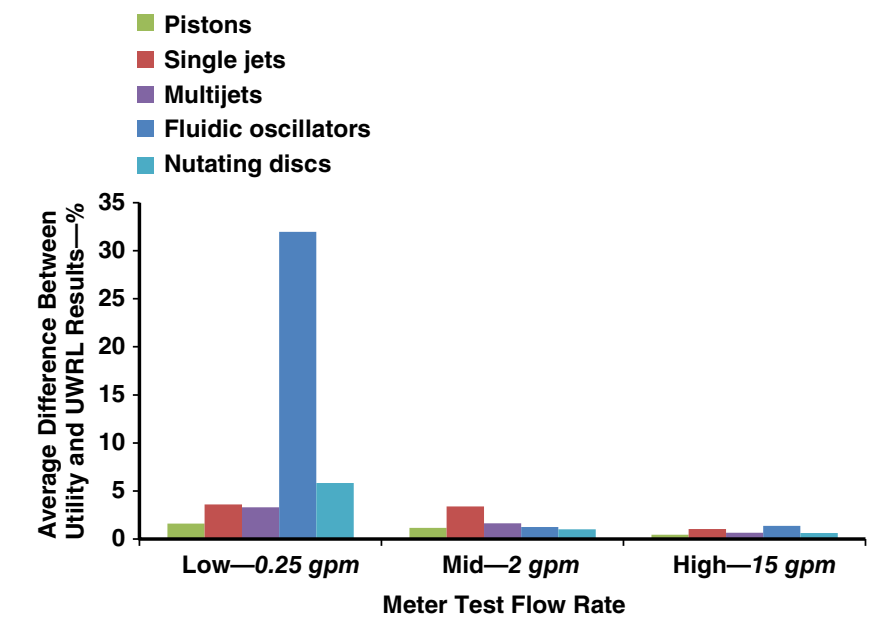

UWRL-Utah Water Research Laboratory
The $5.8 \%$ average difference shown with the ND meters at the minimum test flow rate seemed uncharacteristically high and was found to be the result of an apparent error in one of the utility tests, without which the average difference was reduced to $2.4 \%$. The researchers suspected the error because none of the other tests of that particular meter yielded results near the $20 \%$ accuracy reported for the test in question. None of the other results in this particular test seemed out of the ordinary, so possible sources of the error could include debris lodged in the meter, meter reading error, or trapped air in the meter. Initial flushing of the system before testing and double-checking outlying results can help prevent those errors.

Analysis based on results from DP meter. Because of the many different test setups used in the experiment, it is a challenge to detect testing errors caused by procedural or equipment problems. Because the DP meters demonstrated the least sensitivity to meter sequence, system pressure, and meter spacing, however, it is reasonable to assume that other testing errors may be indicated by analyzing the test results for a single DP meter at each of the utilities. Figures 5-7 show the test results at each utility for a specific DP meter compared with the UWRL test results for that same meter immediately before and after each utility test. Some variation in test results is expected, as shown in the difference between UWRL before-and-after results, because there is some error involved in methods used by each meter type, and testing conditions cannot be exactly replicated; however, analyzing results that fell outside typical ranges can provide insight on easily avoided error sources.

Utilities $1-3,5,7,9$, and 12 tested the same set of meters, so all the results shown on the left side of each plot are for the same meter (DP 1). Utilities 4, 6, 8, 10, and 11 tested the other set of meters, so the results shown for those utilities are also for a single meter (DP 2).

Five of the utility minimum flow-rate test results deviated from the UWRL results by $<1.5 \%$, and three were within about $2 \%$. Because results from utilities 3 and 7 differed from UWRL results more than the others, however, it is likely that the differences may be caused by faulty testing procedures. Tests at low flow rates are most difficult to accurately measure, and the testing agency must use proper test procedures for optimum accuracy. If the volume collected during the minimum flow rate test is too small, then the error of the measurement itself may be much larger than any accuracy deviation in the meter being tested. Figure 5 indicates the likely presence of procedural errors at some of the utilities during the minimum flow rate tests when compared with the same UWRL tests. UWRL staff exercised great care when performing the minimum-flow-rate tests, and each test was conducted using a test volume appropriate for the equipment used.

Although the specific sources of errors in these tests are not readily apparent from the researchers' information, some other common sources of possible testing procedural errors include poor meter installation, register-reading errors, entrained air in the system, collection tank-reading errors (e.g., the volumetric or vernier scale lacks sufficient resolution), varying head or flow rate, and leaks in the test bench plumbing. M6 also mentions that 


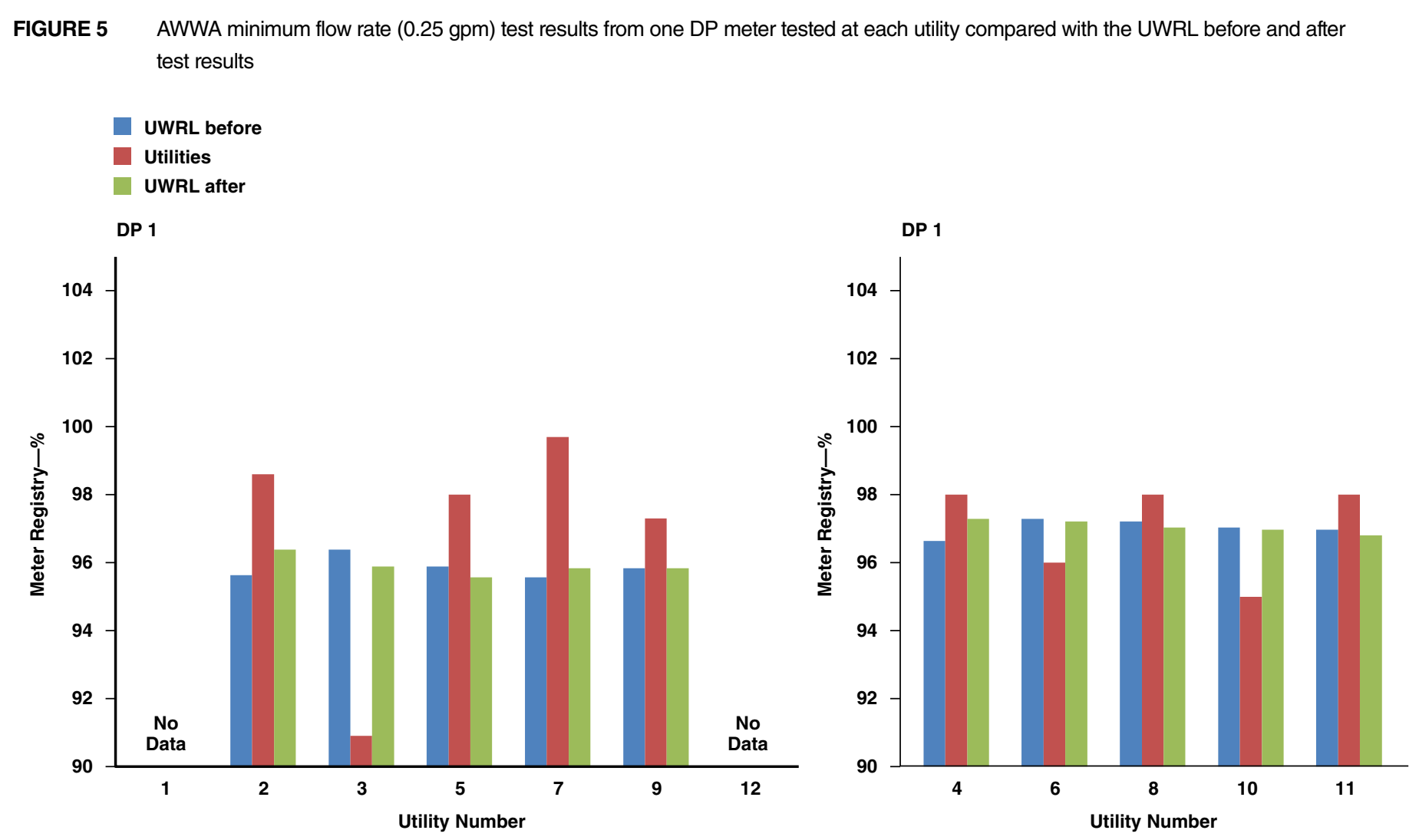

DP—displacement piston, UWRL—Utah Water Research Laboratory

with composite-body meters, excessive clamping force may distort meter measuring chambers.

At the intermediate test flow rate, nine of the 12 utility test results were within $1.5 \%$ of the test results obtained by the UWRL. Utility 3 generated the greatest deviation from the UWRL results when compared with the other utilities. The most probable cause for this discrepancy is the very small test volume (just more than $1 \mathrm{gal}$ ) that was collected by the utility at this flow rate. M6 recommends a test quantity of at least $10 \mathrm{gal}$ or $1 \mathrm{cu} \mathrm{ft}$ of water at this flow rate. In this case, the readability and precision of the gearing (possible backlash or looseness of gear mechanism to allow movement) and pointer position variability make the uncertainty too great to quantify the accuracy with such a small throughput volume.

Using adequate test quantities will reduce the testing errors associated with collection tank scale precision. In addition to providing recommendations for test flow rates and volumes, M6 describes a simple way to determine test volumes based on the desired accuracy of the test. Dividing the scale and reading error by the desired maximum test error (as a fraction) yields the water column height in the tank required to achieve the desired level of test accuracy.

All of the maximum-flow-rate tests, as shown in Figure 7, seemed to use an adequate test quantity. All but three of the utility test results at maximum-flow rates were within $0.5 \%$ of UWRL results.
Effects of test setup on FO meters. The authors conclude that procedural errors and equipment problems had only a marginal effect on the test results at most of the utilities with meter test benches that participated in this study, especially at intermediate and maximum test-flow rates. The authors determined, however, that the most probable cause for the large average differences for the minimum-flow-rate test results shown in Figure 1 for utilities 2, 5, 9, and 10 can be attributed to FO result inconsistency caused by the different test setups. This theory becomes readily apparent when the minimum-test-flow results for the two FO meters are reviewed (see Figure 8).

As previously stated, the minimum-flow-rate test results for the DP meters varied from the UWRL results by a maximum of $5 \%$, whereas there was a much greater difference with the FO meters. For that particular meter type, five of the 12 utilities recorded accuracies of $<80 \%$ at the 0.25 -gpm test-flow rate, and two of those five utilities recorded accuracies approaching $0 \%$. Conversely, the accuracies from the UWRL FO tests at minimum flow rate were consistently around $105 \%$, which is an indication that the variations associated with each utility in Figure 8 can be attributed to something other than the accuracy of the meter.

Referring again to Figure 1, there was also a major difference between the UWRL test results at minimum flow rate and the results obtained by utility 11 , but this is the result of the accuracy of the single ND meter test result previously described. Excluding 


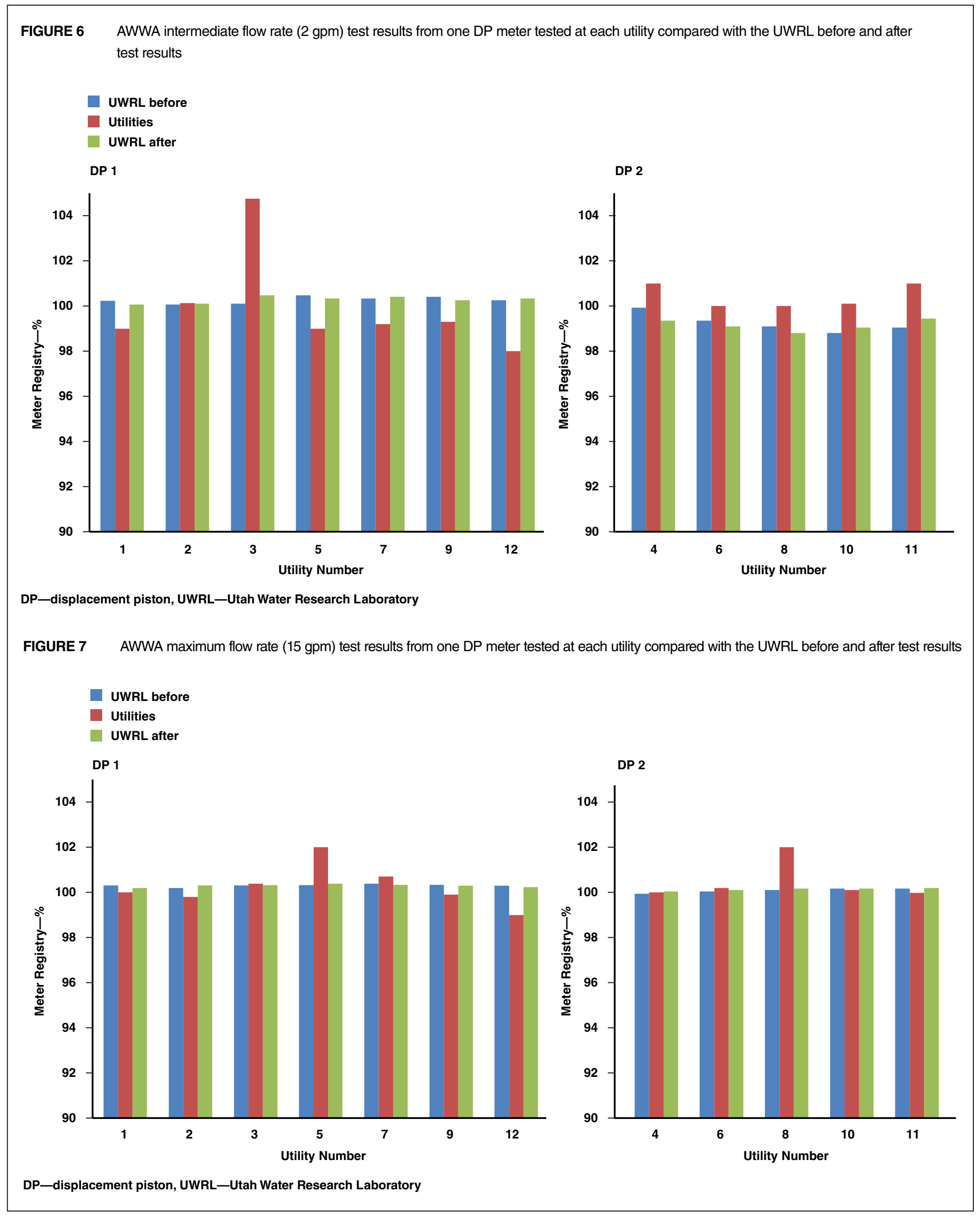




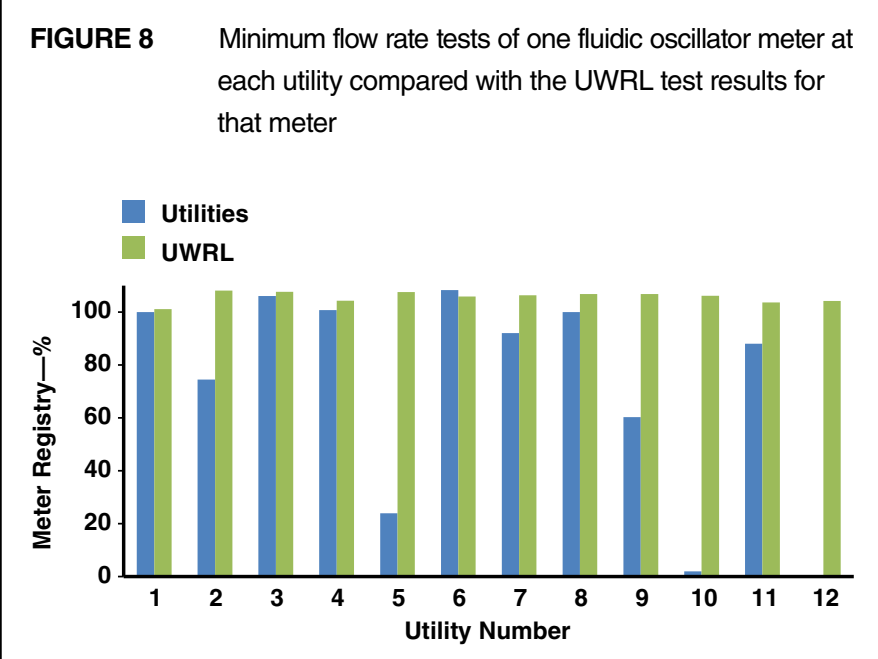

UWRL-Utah Water Research Laboratory

this result and the FO meter results, the minimum-flow-rate test results submitted by the utilities using test benches were reasonably consistent, regardless of meter type.

In an effort to better understand how the specific test-bench setup may have affected the accuracy of FO meters at low-flow rates, the UWRL conducted tests with various setup configurations. UWRL staff confirmed meter sequencing, system pressure, and meter spacing from photographs provided by each utility and from interviews with the utility, and modeled test setups to target the differences that may have accounted for the inconsistent results. Figure 9 shows the results of the tests conducted by the UWRL, in which five scenarios are compared.

\section{FIGURE 9 Test results of different test bench setups using a fluidic oscillation meter at a flow rate of $0.25 \mathrm{gpm}$}

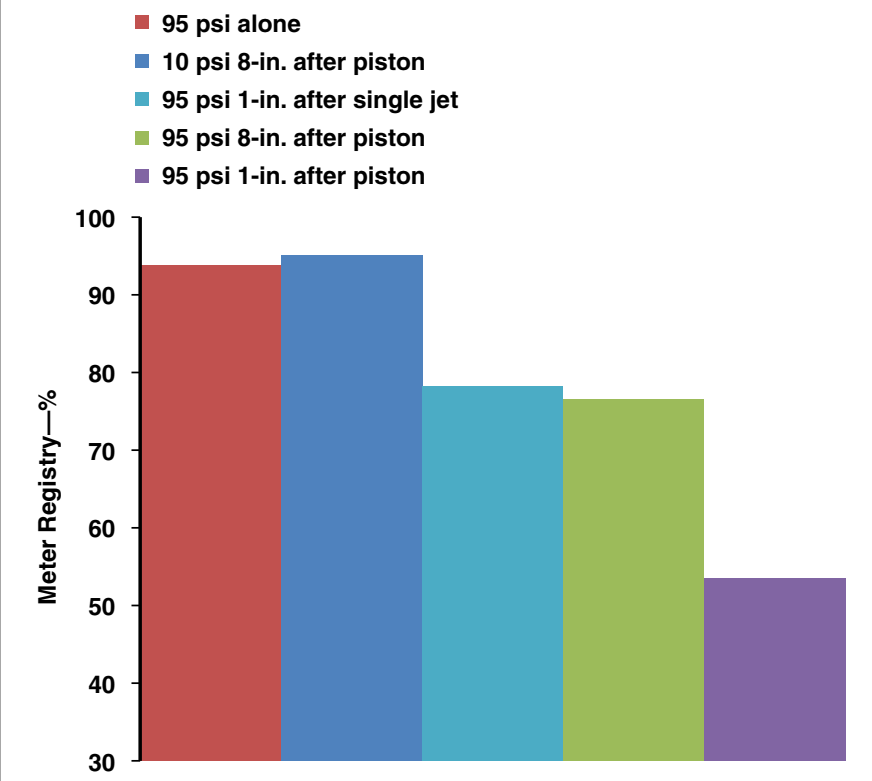

Two of the test setups produced accuracy results around $95 \%$ : first, testing an FO meter by itself with a system pressure of 95 psi; second, testing the FO meter downstream of a DP meter with an 8 -in.-long straight connector and a system pressure of $10 \mathrm{psi}$.

The next two tests shown in Figure 9, which yielded results of 78 and $76.5 \%$, were run with system pressure at 95 psi. The first of these tests was conducted with the FO meter installed directly downstream of an SJ meter, with a 1-in. connector between the meters. The FO meter was 8 in. downstream of a DP meter for the second test.

The last test result in Figure 9 of just $53.5 \%$ resulted from installing the FO meter directly downstream of a DP meter with a system pressure of 95 psi.

The test results showed that these setups reflected the differences that the UWRL noted among the different utility tests. FO registration was affected by flow disturbances associated with upstream meters. The effect seemed to increase with higher system pressure and shorter pipe lengths between the meters. Though the effects caused by the SJ were less pronounced than those of the DP, both meters adversely affected the registration of the FO meter. In order to minimize testing errors associated with these flow disturbances, utilities should avoid testing FO meters downstream of other meters at the minimum flow rate.

\section{CONCLUSIONS}

Analyzing results of water meter accuracy testing as performed by a dozen different utilities provided some useful insight into possible sources of error. First, water meter test benches should be kept clean and in good repair. The authors have seen test benches used as work benches, planters, and for general storage. One test bench being used in a major US city had rags wrapped around the fittings to keep water from spraying the area during a test.

Aside from using properly functioning test equipment, proper procedures are especially critical for accurate meter registry tests. Carefully following guidelines provided in M6 will reduce preventable errors in testing. The results showed that most of the utilities that participated in this study do conduct water meter testing within a moderate level of accuracy.

For the DP meters, five of the 12 utilities recorded meter accuracies to within $1.5 \%$ of UWRL results at the minimum flow rate tested, and five other utilities differed by between 2 and $4 \%$. The intermediate-flow-rate tests showed less variance, with nine of the utilities achieving results that were within $1.5 \%$ of UWRL results; two of the utilities were within $2 \%$, and the remaining utilities' test results were within 5\%. Maximum-flow-rate test results were within $0.5 \%$ for nine of the utilities, and the test results for the remaining three utilities were within $2 \%$ of the UWRL results.

The most noticeable procedural error the researchers observed-particularly at minimum-flow-rate tests-was that some of the utilities collected a test volume that was insufficient to minimize measurement uncertainties. The authors recommend that the Test Quantities section in M6 be observed carefully for each test flow rate in order to minimize measurement errors, especially at minimum flow rates. The use of adequate test 
quantities at minimum flow rates does increase the duration of accuracy tests, and this will magnify errors if there are leaks in the system. As previously noted, test benches should be kept in good repair and free of leaks.

Although just one of the participating utilities (utility 12) used a portable test meter to conduct the accuracy tests, the results clearly showed that in this instance this method was not as accurate as using a standard test bench for testing small meters. This is probably because the accuracy of each test was primarily dependent on the accuracy of the reference test meter. It is also difficult to achieve the maximum-test-flow rate of $15 \mathrm{gpm}$ from a typical residential hose bib. Likewise, secondary-flow measurement devices are not recommended for use as reference test bench flow-measurement devices.

The study also showed that certain meter types are more affected by the test setup than others. The results showed that DP meters were the least affected by meter testing flow disturbances of all the meter types tested. Conversely, FO meters were shown to be significantly affected by certain flow disturbances. A utility testing FO meters may minimize testing errors by avoiding testing downstream of other meters, providing ample straight piping upstream of each meter (approximately five equivalent pipe diameters) and by reducing system pressure.

By adjusting testing procedures to avoid errors caused by insufficient flow volume and/or flow disturbances, utilities may avoid making potentially expensive metering decisions based on inaccurate test data. Further research should be done regarding the effect of flow disturbances on other types of water meters, particularly with the newer, solid-state types of water meters.

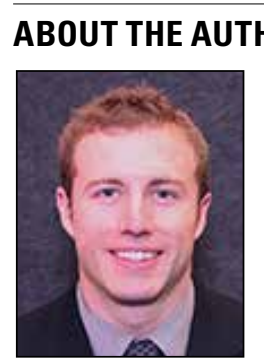

\section{ORS}

Devan J. Shields (to whom correspondence should be addressed) is an analyst with Kimley-Horn and Associates, 801 Cherry St., Ste. 950, Ft. Worth, TX 76102 USA; devan.shields@kimley-horn.com.He completed his master's degree in civil engineering at Utah State University in 2011 after working as a research assistant at the Utah Water Research Laboratory for two years. He has since been serving municipal utilities in the Dallas/Ft. Worth area as an analyst with Kimley-Horn. Steven L. Barfuss and Michael C. Johnson are research assistant professors with the Utah Water Research Laboratory in Logan, Utah. Craig C. Hannah is engineering manager at Johnson Controls Inc. in Lubbock, Texas.

\section{PEER REVIEW}

Date of submission: 02/12/2013

Date of acceptance: 06/26/2013

\section{REFERENCES}

AWWA, 2012. Water Meters-Selection, Installation, Testing, and Maintenance, Manual of Water Supply Practices M6 (5th edition). AWWA, Denver.

Bowen, P.T., 1991. Evaluating Residential Water Meter Performance. AWWA, Denver. 